\title{
Phage display selection on whole cells yields a small peptide specific for $\mathrm{HCV}$ receptor human CD81
}

\author{
Jie $\mathrm{CAO}^{1}$, Ping ZHAO ${ }^{1}$, Xiao Hui MIAO ${ }^{2}$, Lan Juan ZHAO ${ }^{1}$, Li Jun XUE ${ }^{1}$, Zhong Tian QI ${ }^{1, *}$
}

${ }^{1}$ Department of Microbiology, Second Military Medical University, Shanghai 200433, China

E-mail:qizt@smmu.edu.cn

${ }^{2}$ Department of Infectious Diseases, Changzheng Hospital, Second Military Medical University, Shanghai 200003, China

\begin{abstract}
The human CD81 (hCD81), the most recently proposed receptor of hepatitis C virus (HCV), can especifically bind to HCV envelope glycoprotein 2 (E2). In this study, hCD81-expressing murine NIH/3T3 cells were used to select hCD81-binding peptides from a phage displayed nonapeptide library (PVIII9aaCys). Eighteen of the 75 clones selected from the library showed specific binding to the hCD81-expressing NIH/3T3 cells by enzyme linked immunosorbent assay (ELISA) and competitive inhibition test. Twelve out of the 18 clones shared the amino acid motif SPQYWTGPA. Sequence comparison of the motif showed no amino acid homology with the native HCV E2. The motif-containing phages could competitively inhibit the ability of HCV E2 binding to native hCD81-expressing MOLT-4 cells, and induce HCV E2 specific immune response in vivo. These results suggest that the selected motif SPQYWTGPA should be a mimotope of HCV E2 to bind to hCD81 molecules. Our findings cast new light on developing HCV receptor antagonists.
\end{abstract}

Key words: viral receptor, hepatitis C virus, cell-based selection, hCD81-binding peptide, phage display.

\section{INTRODUCTION}

Hepatitis $\mathrm{C}$ virus (HCV), a most common causative agent for post-transfusional hepatitis, is a positivestranded RNA virus, classified as family Flavivirida[1]. Although the virus was identified more than a decade ago, some events in cell entry, replication and morphogenesis have not been well understood. It has been demonstrated that HCV envelope glycoprotein 2 (E2) could bind to host cells by interacting with the CD81 molecule [2]. CD81 is a membrane protein of $26000 \mathrm{KD}$, and with four transmembrane (TM) and two extracellular (EC) domains, it belongs to the tetraspanin superfamily [3]. The larger extracellular loop (LEL) of CD81 molecule contains four conservative cysteine residues forming two disulfide bounds that maintain natural configuration of the protein. CD81 is expressed on most human cells and is demonstrated to play a role in cell adhesion, pro-

\footnotetext{
"Corresponding author: Zhong Tian QI, Department of Microbiology, Second Military Medical University, 800 Xiangyin Road, Shanghai 200433, China. Tel/fax: 0086-21-25070312; E-mail: qizt@smmu.edu.cn Received Jan-21-2003 Revised Aug-10-2003 Accepted Sep-15-2003
}

liferation, activation and differentiation[4-6]. Although the mechanism involving in the cell entry of $\mathrm{HCV}$ was not known clearly, human CD81 (hCD81) was considered as a putative $\mathrm{HCV}$ receptor[7-10]. Because no effective chemical reagents are available for the prevention of HCV infection, a phage displayed peptide library was used in this study to identify small peptides which are able to selectively block the interaction between hCD81 and HCV E2.

The phage display technique has some advantages in the study of protein-protein interaction[11-13]. And lots of antagonists were identified from phage displayed peptide libraries, such as urokinase receptor antagonists and the human type I interleukin (IL)-1 receptor antagonist [14-17]. However, there are some difficulties for membrane receptors to be purified and maintain the natural conformation. It is better to use whole native cells or target receptor gene transfected cells to select the ligands[18, 19]. Whole cells usually maintain the native conformation of receptor with normal posttranslational modification, so so the ligands of receptor can be selected even without 
the information about the receptor.

In this study, hCD81-expressing murine NIH/3T3 cells were used to select hCD81-binding peptides from a phage peptide library. A small peptide specific for hCD81 was identified which is potential for development of $\mathrm{HCV}$ receptor antagonists.

\section{MATERIALS AND METHODS}

\section{Cell lines}

The murine fibroblast cell line NIH/3T3 (ATCC, Rockville, MD) were cotransfected with the eukaryotic expression vector pCDM8hCD81 containing a full-length hCD81 cDNA (kindly provided by Dr. Levy S, Stanford University) and pSV2neo helper plasmid (ClonTech, Palo Alto, CA, USA) to obtain hCD81-expressing cells (NIH/3T3-hCD81)[20]. NIH/3T3-hCD81 and NIH/3T3 cells were cultured in RPMI-1640 medium supplemented with $10 \%(\mathrm{v} / \mathrm{v})$ heatinactivated fetal bovine serum (FBS), $100 \mathrm{U} / \mathrm{ml}$ of penicillin and 100 $\mathrm{mg} / \mathrm{ml}$ of streptomycin. Human acute lymphoblastic leukemia cell line MOLT-4 and human hepatocyte line HL-7702, expressing native hCD81 molecules on cell membrane and hCD81-deficient cell line, human histiocytic lymphoma cells U937, were cultured in Dulbecco's modified Eagle's medium (DMEM) supplemented with $15 \%(\mathrm{v} / \mathrm{v}) \mathrm{FBS}, 100 \mathrm{U} / \mathrm{ml}$ of penicillin and $100 \mathrm{mg} / \mathrm{ml}$ of streptomycin. Medium and supplements, with the FBS, were all from GIBCOBRL, Gainthersburg, MD, USA.

\section{Phage peptide library and bacterial strain}

Phage peptide library (PVIII9aaCys) was composed of random circular nonamers, which were fused to the $\mathrm{N}$ terminus of the major coat protein PVIII displayed on filamentous phage f1[21]. Host bacterial strain XL1-blue was from Stratagene Company, Cambridge, England.

\section{Selection of phage peptide library with NIH/3T3 hCD81 cells}

Selection procedure was according to Pelsers and Souriau with some modifications[22, 23]. Briefly, phages of approximate $4 \times 10^{10}$ phage transducting unit (TU) were preincubated for $1 \mathrm{~h}$ with blocking -buffer $\left(5 \mathrm{mg} / \mathrm{ml}\right.$ bovine serum albumin (BSA), $0.1 \mathrm{~mol} / \mathrm{L} \mathrm{NaHCO}_{3}$ ) and then with $1 \times 10^{6}$ of wild type NIH/3T3 cells. After centrifugation at $10,000 \mathrm{rpm}$ for $5 \mathrm{~min}$ at $4^{\circ} \mathrm{C}$, the supernatant was transfered to a $35 \mathrm{~mm}$ cell culture plate (Nunc, Roskilde, Denmark), on which $3.5 \times 10^{5}$ $\mathrm{NIH} / 3 \mathrm{~T} 3-\mathrm{hCD} 81$ cells were grown, and incubated for $2 \mathrm{~h}$. Unbound phage particles were removed by washing with $0.1 \%$ TBST $(50 \mathrm{mM}$ Tris-HCl, pH 7.5, $150 \mathrm{~m} M \mathrm{NaCl}, 0.1 \%$ Tween 20). Cell-bound phages were eluted with $100 \mathrm{~m} M$ Glycine- $\mathrm{HCl}(\mathrm{pH} 2.2)$ for $10 \mathrm{~min}$, and neutralized with $1 M$ Tris/ $\mathrm{HCl}(\mathrm{pH} 9.0)$. The eluted phages were replicated by infecting Escherichia coli XL1-blue cells, rescuing with M13KO7 helper phages (Pharmacia Biotech, Uppsala, Sweden). The amplified phage particles were purified using polyethyleneglycol (PEG)[24], and then used for the subsequent round of selection with NIH/3T3-hCD81 cells. Four rounds of selection were performed as above.

\section{Whole-cell ELISA}

The exponentially growing NIH/3T3, NIH/3T3-hCD81 or MOLT4 cells were fixed on 96-well microtitration plates (Nunc, Roskilde, Denmark) (about $3 \times 10^{5}$ cells/well) with $1 \mathrm{mg} / \mathrm{ml}$ of polylysine. Amplified phage clones were randomly picked after the fourth round of selection with the preincubation for $1 \mathrm{~h}$ with $3 \%$ BSA. About $2 \times 10^{11}$ TU of phages were added to each well, and then incubated with the cells for $2 \mathrm{~h}$ at room temperature. The wells were washed extensively with $0.1 \%$ TBST and the amount of bound phages was detected with horseradish peroxidase (HRP)-conjugated anti-M13 phage antibody (Pharmacia Biotech, Uppsala, Sweden). The development was performed by the addition of 3, 3', 5, 5'-tetramethylbenzidine (TMB) (Sigma, St. Louis, MO, USA), and read at $450 \mathrm{~nm}$ in an ELISA Reader (Bio Rad). Helper phage M13KO7 and original phage peptide library PVIII9aaCys were used as negative controls.

\section{Competitive ELISA}

MOLT- 4 cells were fixed about $3 \times 10^{5}$ cells per well on 96-well microtitration plates using polylysine. Anti-hCD81 monoclonal antibody (Pharmacia) and positive phage particles $\left(5 \times 10^{12} \mathrm{TU} / \mathrm{ml}\right)$ were mixed and then added to each well. After $1 \mathrm{~h}$ of incubation, the wells were washed with $0.1 \% \mathrm{TBST}$, and incubated at $37^{\circ} \mathrm{C}$ for $1 \mathrm{~h}$ in the presence of HRP-conjugated anti-M13 phage antibody (1:5000 diluted). Finally, the wells were developed with substrate TMB, and read at $450 \mathrm{~nm}$.

\section{Sequence analyses}

DNA phagemids were prepared from identified phage clones by standard method[25] and sequenced with ABI Prism kit (Perkin Elmer Applied Biosystems, USA) automaticly. The primer used for sequencing is 5'-CCCACGCATAACCGATA-3'. Corresponding amino acid sequences were deduced from DNA sequences, and a multiple sequence alignmemt was done using BLAST software package provided by http://ncbi.nlm.nih.gov./BLAST/ to determine the groups of related peptides. Homologous analysis was performed to find an optimal alignment between the selected motifs and the primary sequence of HCV E2.

\section{Specific analyses of positive phages binding to hCD81 protein}

\section{Competitive inhibition test}

Native hCD81-expressing MOLT-4 cells were fixed on 96-well microtitration plates about $3 \times 10^{5}$ cells per well and blocked for $1 \mathrm{~h}$ with 3\% BSA. HCV E2 antigen (kindly provided by Dr. Donnelly III JJ, Chiron Company, USA) and positive phages in serial dilutions were added to each well and incubated for $1 \mathrm{~h}$ at room temperature. After washing with $0.1 \%$ TBST, the cell-bound phages were detected with HRP-conjugated anti-M13 phage antibody (Pharmacia Biotech, Uppsala, Sweden). And the cell-bound HCV E2 was detected with mouse anti-HCV E2 mAb (kindly provided by Dr. Donnelly III JJ) and HRP-conjugated goat anti-mouse IgG (Sigma, St. Louis, MO, USA). 


\section{Immunohistochemistry}

Exponentially growing MOLT-4, HL-7702 or U937 cells (about $3.5 \times 10^{5}$ cells per well) were cultured respectively with positive phage particles (about $1 \times 10^{11} \mathrm{TU}$ ) for $2 \mathrm{~h}$ at room temperature. The cells were washed extensively with phosphate-buffered saline (PBS), swung onto the glass slides, and then fixed with acetone. The glass slides were incubated with HRP-conjugated anti-M13 phage antibody at $37^{\circ} \mathrm{C}$ for $1 \mathrm{~h}$. After washed with PBS, the slides were developed with diaminobenzidine (DAB), counterstained lightly with hematine crystal, dehydrated through a graded series of ethanol to xylene, and coverslipped with permount.

\section{Immunization of mice and ELISA}

The purified positive phage particles were resuspended with $0.9 \%$ $\mathrm{NaCl}$ at a concentration of 1 쪼 $10^{13} \mathrm{TU} / \mathrm{ml}$. Four-to-six-week old female C57BL/6 mice (Experimental Animal Center, SMMU, China) were immunized by i. p. injection with $200 \mu$ of positive phage emulsion (1:1 with complete Freund's adjuvant). Same dosages with incomplete Freund's adjuvant were used for the booster at weeks 4 and 7 . The animals were bled for titer detection on the 10th day after second and third injections.

Microtitration plates were coated with $0.1 \mu \mathrm{g} /$ well of HCV E2 and blocked with $3 \% \mathrm{BSA}$ for $2 \mathrm{~h}$ at $4^{\circ} \mathrm{C} .150 \mu \mathrm{l}$ mouse serum of different dilutions was added to each well, and incubated for $1 \mathrm{~h}$ at $37^{\circ} \mathrm{C}$. After washed with PBS, the cells were incubated with HRPconjugated goat anti-mouse IgG (Sigma) for $40 \mathrm{~min}$ at $37^{\circ} \mathrm{C}$. The development was performed by addition of substrate TMB, and read at $450 \mathrm{~nm}$. For competition assay, $150 \mu \mathrm{l}$ of positive serum (diluted 1:100) from immunized mice were mixed with a graded series of HCV E2 antigen and added to HCV E2 coated microtitration plates. Normal mouse serum and equal volume of PBS were used as controls.

\section{RESULTS}

\section{Specific enrichment of positive phages}

In order to enrich hCD81-binding phages from the phage peptide library, four rounds of selection with NIH/ 3T3-hCD81 cells were performed. The enrichment was determined by the use of the output/input ratio of phages after each round of selection. The ratio increased about 8 -fold (from $2.3 \times 10^{-6}$ to $1.9 \times 10^{-5}$ ) after the second round

Tab 1. Enrichment of phages for each round of selection from phage displayed nonapeptide library

\begin{tabular}{cccc}
\hline $\begin{array}{c}\text { Rounds } \\
\text { (input) }\end{array}$ & $\begin{array}{c}\text { Slected phages (TU*) } \\
\text { (output) }\end{array}$ & $\begin{array}{c}\text { Eluted phages (TU) } \\
\text { (out/input) }\end{array}$ \\
\hline 1 & $4.8 \times 10^{10}$ & $1.1 \times 10$ & $2.3 \times 10^{-6}$ \\
2 & $4.2 \times 10^{10}$ & $8.0 \times 10^{5}$ & $1.9 \times 10^{-10}$ \\
3 & $3.3 \times 10^{10}$ & $2.2 \times 10^{7}$ & $6.7 \times 10^{-4}$ \\
4 & $4.0 \times 10^{10}$ & $3.7 \times 10^{8}$ & $9.3 \times 10^{-3}$ \\
\hline
\end{tabular}

* TU: transducting unit of selection. After the third and the fourth rounds of selection, the output/input ratio of phages increased about 290-fold and 4, 000 fold, respectively (Tab 1), which indicates an obvious enrichment for the specific binding of phages to hCD81-expressing cells.

\section{Identification of the positive phages}

75 clones were picked out from the sample after fourth round of selection, and the specificity was examined by whole-cell ELISA. Thirty of the 75 clones (40\%) showed the binding ability to NIH/3T3-hCD81 cells and native hCD81-expressing MOLT-4 cells (data not shown). In contrast, the original phage library and helper M13KO7 phages cannot bind to the above 2 types of cells. Competitive inhibition test further demonstrated that 18 out of the 30 positive clones could specifically inhibit the binding of anti-hCD81 MAb to MOLT-4 cells. Mean inhibition ratio of the 18 clones was $70 \%$ (Fig 1).

\section{Analyses of exogenous sequences of positive phage clones}

The exogenous DNA sequences of 18 positive phage clones were determined by DNA sequencing. The deduced

Tab 2. Exogenous amino acid sequences (deduced from DNA sequences) of the nonapeptides in PVIII coat proteins of positive phage clones selected from PVIII9aaCys peptide library

\begin{tabular}{cc}
\hline Phage clones & Amino acid sequences \\
\hline C4 & C SPQYWTGPA C \\
C9 & C SPQYWTGPA C \\
C14 & C SPQYWTGPA C \\
C20 & C SPQYWTGPA C \\
C25 & C SPQYWTGPA C \\
C28 & C SPQYWTGPA C \\
C38 & C SPQYWTGPA C \\
C53 & C SPQYWTGPA C \\
C58 & C SPQYWTGPA C \\
C60 & C SPQYWTGPA C \\
C65 & C SPQYWTGPA C \\
C73 & C SPQYWTGPAC \\
C7 & C VQFPTSEKM C \\
C35 & C SDPRKMCIY C \\
C41 & C IWENAGRMV C \\
C46 & C HAGTFLQVA C \\
C54 & C LVAQINLEM C \\
C64 & C ERHTKFPSV C
\end{tabular}

Each end of the exogenous nonapeptides is linked with one cystein residue (C). Single letter abbreviations of amino acids: A, Ala; C, Cys; D, Asp; E, Glu; F, Phe; G, Gly; H, His; I, Ile; K, Lys; L, Leu; M, Met; N, Asn; P, Pro; Q, Glu; R, Arg; S, Ser; T, Thr; V, Val; W, Trp; and Y, Tyr. 


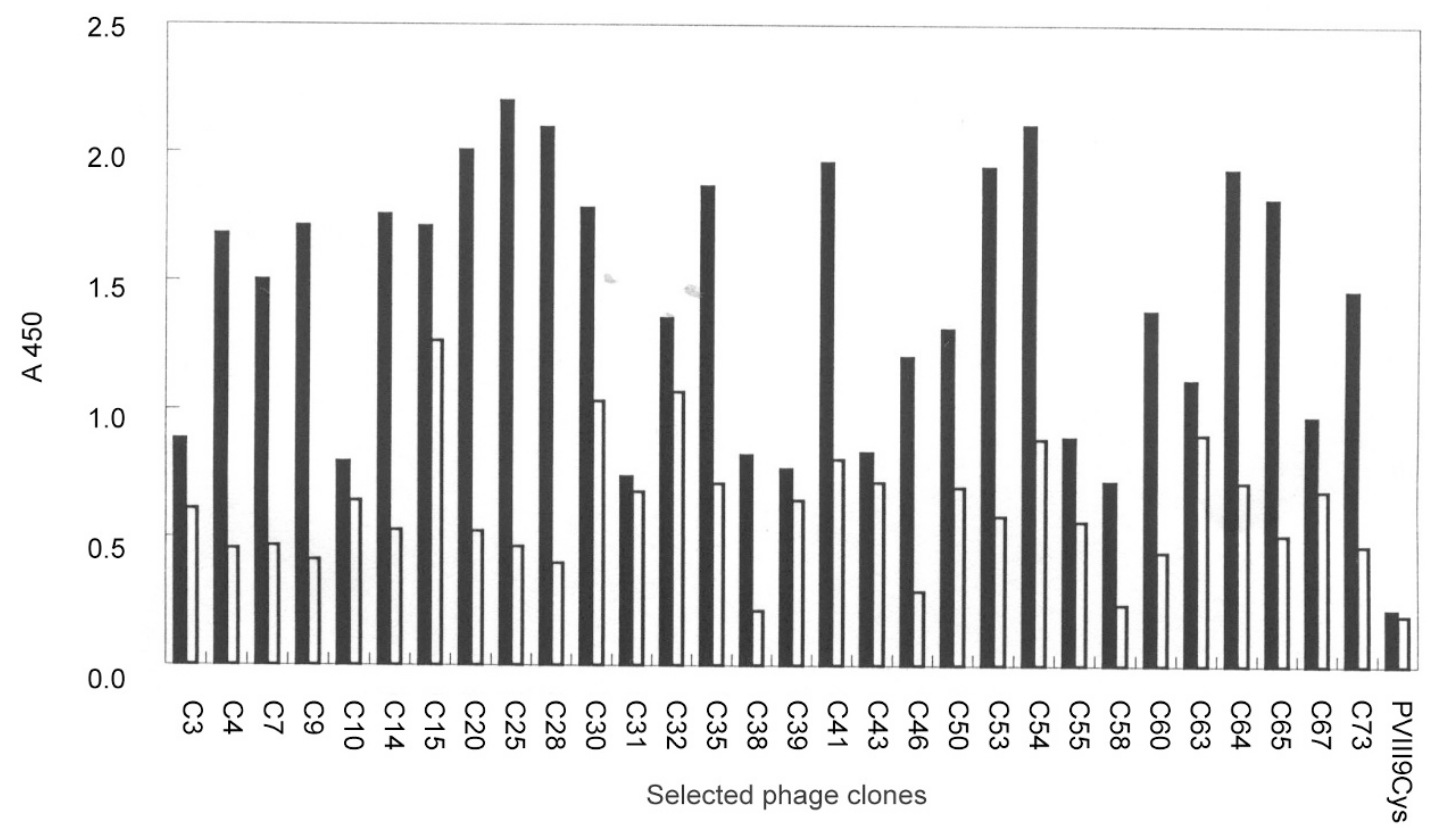

Fig 1. Inhibition of 30 selected phage clones binding to MOLT-4 cells with anti-hCD81 MAb by competitive ELISA. Phage clones binding to MOLT-4 cells were detected by horseradish peroxydase (HRP)-conjugated anti-M13 phage antibody in the presence (white bars) or absence (black bars) of anti-hCD81 MAb. The original phage peptide library PVIII9aaCys without selection was used as a negative control. Average values from two independent experiments are shown.

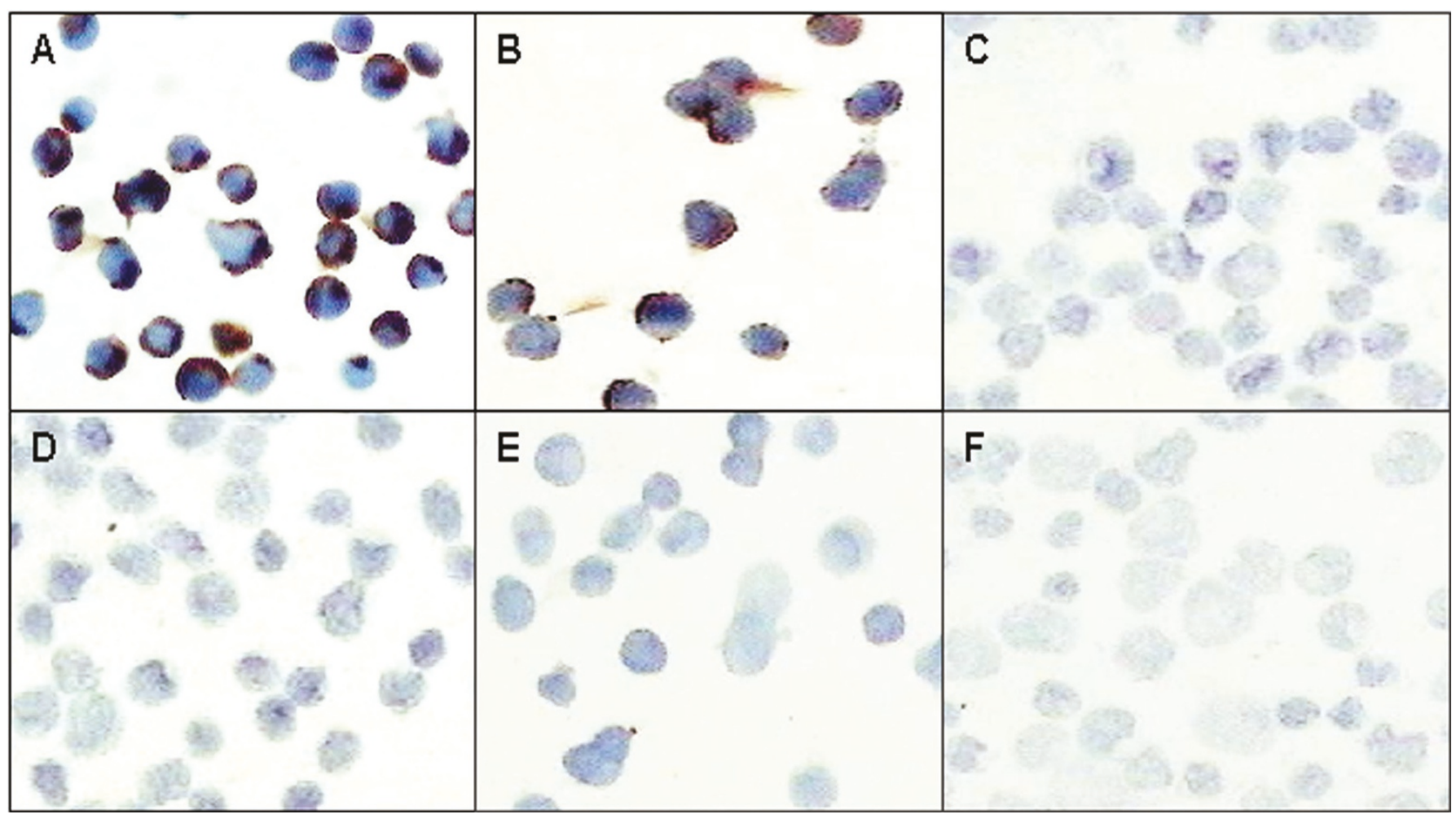

Fig 2. Immunohistochemical staining of hCD81-containing cells bound with the motif-containing phage clone C25. Cell-bound phages were detected using horseradish peroxidase (HRP)-conjugated anti-M13 phage. The positive phages showed binding to MOLT-4 cells (A) and HL7702 cells (B), but not to U937 cells (C). Primary phage peptide library PVIII9aaCys without selection was used as negative control, showing no binding to MOLT-4 cells (D), HL-7702 cells (E) and U937 cells (F). The cells were stained by diaminobenzidine (DAB) followed by hematine crystal. $(10 \times 40)$ 
peptide sequences from DNA sequences were shown in Tab 2. Of the 18 clones, 12 shared the motif SPQYWTGPA. The motif did not show any homology to HCV E2, which implied that the motif should be a mimic sequence of HCV E2 able to bind to hCD81 molecules on cell membrane.

\section{The motif-containing phages specific to hCD81 on cell membrane}

The interaction of the motif-containing phages and several human cell samples was detected by immunohistochemistry staining. Positive phages showed binding to MOLT-4 cells (Fig 2A) and HL-7702 cells (Fig 2B), and dark brown positive staining was seen with phage antibodies on the surfaces of these cells. In contrast, no positive staining was observed on the hCD81-deficient U937 cells (Fig 2C). Primary phage peptide library without selection was used as negative control, while, no positive staining was observed on the surfaces of MOLT4 cells (Fig 2D), HL-7702 cells (Fig 2E) and U937 cells (Fig 2F).

The ability of the motif-containing phages to block the binding of the hCD81-expressing cells with HCV E2 was

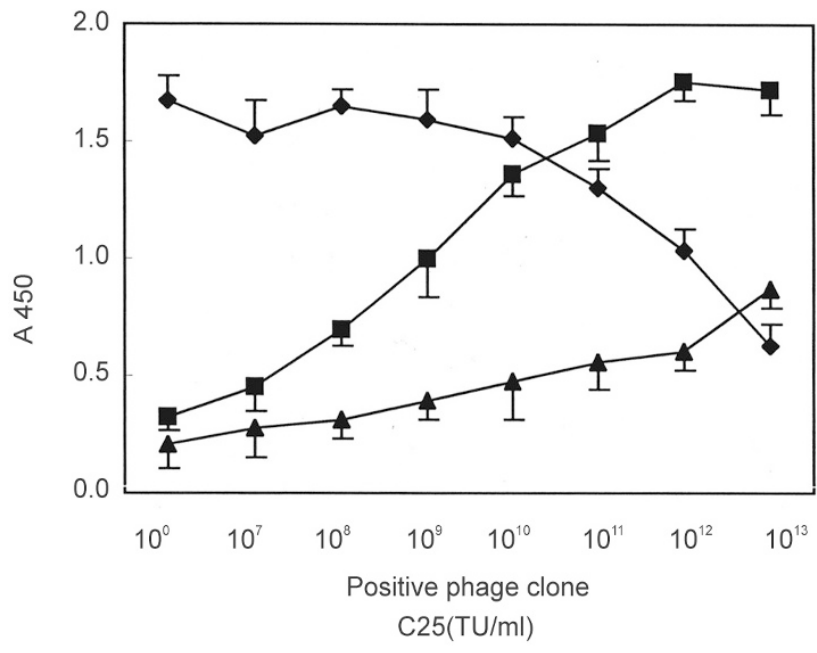

Fig 3. Competitive binding inhibition between positive phages and MOLT-4 cells by HCV E2 protein. MOLT-4 cells were fixed on 96well microtitration plates using polylysine. Inhibition of HCV E2 binding to MOLT- 4 cells was observed by increasing titers of positive phage clone $\mathrm{C} 25$. The cell-bound phages were detected by ELISA with horseradish peroxidase (HRP)-conjugated anti-M13 in the presence ( $\boldsymbol{\Delta}$ ) or absence ( $\boldsymbol{\square}$ ) of HCV E2. The cell-bound HCV E2 were detected by anti-HCV E2 and HRP-conjugated goat anti-mouse IgG $(\checkmark)$. The data represent the mean values of triplicate measurements from a single experiment; error bars represent the standard error of triplicate samples. Comparable data are obtained in three independent experiments. determined by competitive ELISA. The phage clone C25, with the highest (81\%) effect to block the binding of antihCD81 MAb to MOLT-4 cells, was chosen for the test. It was found that the binding ability of the clone $\mathrm{C} 25$ with MOLT-4 cells increased with the increasing amount of the phages. However, the binding of the phages with MOLT-4 cells decreased significantly in the presence of HCV E2 $(2 \mathrm{mg} / \mathrm{ml})$. Similarly, the binding of HCV E2 to MOLT- 4 cells was inhibited by the motif-containing phages in a dose-dependent manner too (Fig 3).

\section{Immunogenic mimicry of HCV E2 epitope}

The motif-containing phages were used for the immunization of C57BL/6 mice. Ten days after the third immunization, the mouse sera were collected and analyzed by titer detection. The sera could react with HCV E2. Furthermore, the reaction of HCV E2 with the sera decreased significantly in the presence of HCV E2 antigen (Fig 4).

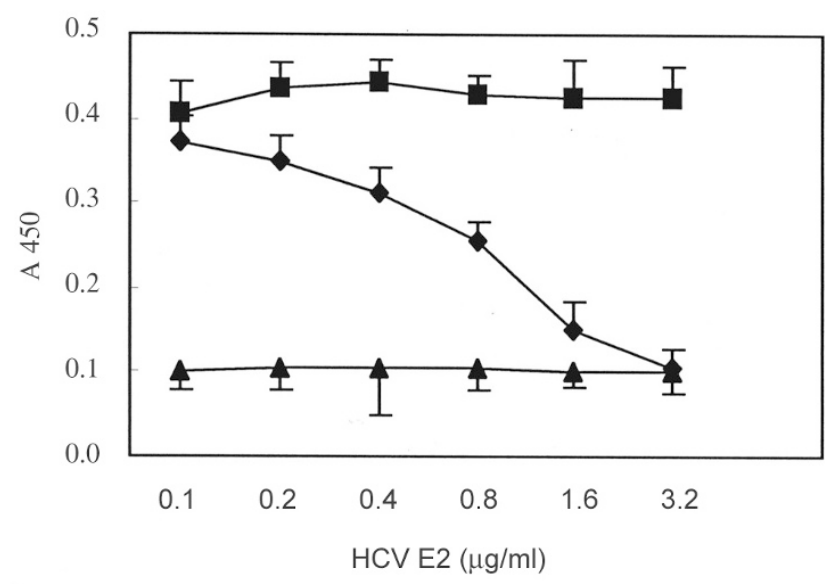

Fig 4. Competitive ELISA reactivity of HCV E2 with the sera from the mice immunized with phage clone $\mathrm{C} 25$ in the presence of HCV E2. HCV E2 antigen was coated onto microtitration plates. The binding of HCV E2 to the sera (diluted 1/100) from the mice immunized with positive phages was detected with horseradish peroxidase (HRP)conjugated goat anti-mouse IgG by the addition of different concentrations of HCV E2 antigen( $\bullet$ ) equal volume of solvent $\operatorname{PBS}(\boldsymbol{\square})$. Normal mouse serum (diluted 1/100) was used as a control $(\mathbf{A})$. The data represent the mean values of triplicate measurements from a single experiment; error bars represent the standard error of triplicate samples. Comparable data are obtained in three independent experiments.

\section{DISCUSSION}

It has been proved that the phenylalanine (Phe) at amino acid (aa) 186 of hCD81 large extracellular loop plays a 
key role in recognition for CD81 binding to HCV E2. Binding site of HCV E2 for hCD81 is a conformational structure naturally involving aa 480 to 493 and 544 to 551 within the E2 protein[3, 7, 26]. Thus it is difficult for a linear peptide library to mimic the discontinuous epitopes of HCV E2 protein. In this work, a conformational constrained peptide library was used, in which each end of the exogenous random nonapeptides is linked with one cystein residue, so circular disulfide-bonded constrained conformation can be formed in the peptide library. It has been reported that the phage displayed constrained library has high affinity with receptor and is easy to be selected for functional peptides or structural mimetics of proteins[16, 27, 28]. Wrighton and colleagues have obtained the ligands of erythropoietin (EPO) receptor from this kind of phage random circular octapeptide library[29]. However, some cell membrane receptors such as CD81 are rarely used possibly because it is difficult for them to maintain the natural conformation or topostructure. Therefore, we established an hCD81-expressing NIH/3T3 cell line for the selection of hCD81binding peptides from the phage peptide library. The major problem existed in cell-based selection is that phage displayed peptides can bind to the modified cells nonspecifically. In order to overcome the problem, multirounds of selection were carried out in our experiment according to Smith's method[30]. In addition, before each round of selection, wild type hCD81-deficient NIH/ 3T3 cells were used for preincubation with the library in order to remove the non-specific phages. Specific phages for binding to hCD81- expressing cells were obtained from the phage peptide library and further enriched round by round.

The phage clones were further identified after the fourth round of selection by whole-cell ELISA and competitive inhibition test. The binding activity between 18 positive clones and hCD81-expressing MOLT-4 cells could be inhibited by the anti-hCD81 MAb. It has been proved that the MAb used in this study can block the site of HCV E2 binding to hCD81[2], thus indicating these 18 clones should be of the same determinant as HCV E2. Although the DNA sequences of these 18 clones were not identical, 12 out of the phage clones displayed the amino acid motif SPQYWTGPA. The motif did not show any homology to the primary sequence of native HCV E2 as we had expected. However, the immunohistochemistry staining showed that the motif-containing phages could bind to MOLT- 4 and HL-7702 cells, both of which express native hCD81, but do not bind to hCD81-deficient U937 cells. Furthermore, the motif-containing phages could inhibit the ability of HCV E2 binding to MOLT- 4 cells in a competitive manner. These results demonstrate that the selected motif SPQYWTGPA should be a mimotope of HCV E2 to bind to hCD81 molecules.

If the motif displayed on the selected phages mimics HCV E2 epitope, it should be immunogenic mimics of the natural antigen. To verify this inference, the purified motif-containing phage particles were used as antigen to immunize C57BL/6 mice. Compared with the control, the immunized mice showed an obvious humoral immune response against HCV E2 antigen. The specificity of the response was further identified by a competition assay, and the results showed that the reaction of the phages with the mouse serum was significantly inhibited in the presence of HCV E2. These results suggest that the motif SPQYWTGPA might mimic the structural epitope of HCV E2 and provide the potential for further development of $\mathrm{HCV}$ receptor antagonists.

\section{ACKNOWLEGMENTS}

We thank Dr. Monaci P (Istituto di Ricerche di Biologia Molecolare P. Angeletti SPA, Rome, Italy) for kindly providing the phage-displayed circular nonapeptide library and Dr. Donnelly III. JJ (Chiron Company, USA) for HCV E2 protein and anti-HCV E2 MAb.

This work was financially supported by research grants from the National Natural Science Foundation of China (No. 30271187) and the Shanghai Science and Technology Development Foundation (No. 02DJ14015).

\section{REFERENCES}

1 Kato N, Hijikta M, Ootsuyma Y, et al. Molecular cloning of the human hepatitis $\mathrm{C}$ virus genome from Japanese patients with non-A, non-B hepatitis. Proc Natl Acid Sci USA 1990; 87(24): 9524-8.

2 Pileri P, Uematsu Y, Campagnoli S, et al. Binding of hepatitis C virus to CD81. Science 1998; 282:938-40.

3 Higginbottom A, Quinn ER, Kuo CC, et al. Identification of amino acid residues in CD81 critical for interaction with hepatitis C virus envelope glycoprotein E2. J Virol 2000; 74:3642-9.

4 Oren R, Takahashi S, Doss C, Levy R, Levy S. TAPA-1, the target of an antiproliferative antibody, defines a new family of transmembrane proteins. Mol Cell Biol 1990; 10(8):4007-15.

5 Tachibana I, Hemler ME. Role of transmembrane 4 super-family (TM4SF) proteins CD9 and CD81 in muscle cell fusion and myotube maintenance. J Cell Biol 1999; 146(4):893-904.

6 Cao J, Qi ZT. CD81: a novel receptor of hepatitis C virus. Natl 
Med J China 2001; 81(2):126-7.

7 Flint M, Maidens C, Loomis-price LD, et al. Characterization of hepatitis C virus E2 glycoprotein interaction with a putative cellular receptor, CD81. J Virol 1999; 73:6235-44.

8 Di Bisceglie AM. Hepatitis C- viology and future antiviral targets. Am J Med 1999; 107(6B):45S-S.

9 Flint M, Dubuisson J, Maidens C, et al. Functional characterization of intracellular and secreted forms of a truncated hepatitis C virus E2 glycoprotein. J Virol 2000; 74:702-9.

10 Petracca R, Falugi F, Galli G, et al. Structure-function analysis of hepatitis C virus envelope-CD81 binding. J Virol 2000; 74:482430 .

11 Cesareni G, Csatagnoli L, Cestra G. Phage displayed peptide libraries. Comb-chem- high-throughput-screen. 1999; 2(1):117.

12 Zwick MB, Shen J, Scott JK. Phage-displayed peptide libraries. Curr Opin Biotechnol 1998; 9 (4):427-36.

13 Choi JY, Lee SH, Park CY, et al. Identification of calmodulin isoform-specific binding peptides from a phage-displayed random 22-mer peptide library. J Biol Chem 2002; 277 (24):216308.

14 Goodson RJ, Doyle MV, Kaufman SE, et al. High-affinity urokinase receptor antagonists identified with bacteriophage peptide library. Proc Natl Acad Sci USA 1994; 91:7129-33.

15 Akeson AL, Woods CW, Hsieh LC, et al. AF 12198, a novel low molecular weight antagonist, selectively binds the human type I interleukin (IL)-1 receptor and blocks in vivo responses to IL-1. J Biol Chem 1996; 271:30517-23.

16 O’Neil KT, Hoess RH, Jackson SA, et al. Identification of novel peptide antagonists for GP II b/ IIIa from a conformationally constrained phage peptide library. Proteins 1992; 14 (4):50915.

17 Koivunen E, Gay DA, Ruoslahti E. Selection of peptides binding to the a5b1 integrin from phage display library. J Biol Chem 1993; 268:20205-10.

18 Szardenings M, Tornroth S, Mutulis F, et al. Phage display selection on whole cells yields a peptide specific for melanocortin receptor 1. J Biol Chem 1997; 272(44):27943-8.

19 Binetruy-Tournaire R, Demangel C, Malavaud B, et al. Identi- fication of a peptide blocking vascular endothelial growth factor (VEGF)-mediated angiogenesis. EMBO J 2000; 19(7):152533.

20 Cao J, Zhao P, Zhao LJ, et al. Identification and expression of human CD81 gene on murine NIH/3T3 cell membrane. J Microbiol Methods 2003; 54(1):81-5.

21 Prezzi C, Nuzzo M, Meola A, et al. Selection of antigenic and immunogenic mimics of hepatitis $\mathrm{C}$ virus using sera from patients. J Immunol 1996; 156:4504-13.

22 Pelsers MMAL, Lutgerink JT, Nieuwenhoven FAV, et al. A sensitive immunoassay for rat fatty acid translocase (CD36) using phage antibodies selected on cell transfectants: abundant presence of fatty acid translocase/CD36 in cardiac and red skeletal muscle and up-regulation in diabetes. Biochem J 1999; 337: 407-14.

23 Souriau C, Gracy J, Chiche L, et al. Direct selection of EGF mutants displayed on filamentous phage using cells overexpressing EGF receptor. Biol Chem 1999; 380:451-8.

24 Marks JD, Hoogenboom HR, Boonet TP, et al. By-passing immunization. Human antibodies from $\mathrm{V}$-gene libraries displayed on phage. J Mol Biol 1991; 222:581-97.

25 Sambrook J, Fritsch EF, Maniatis T. Molecular cloning: A laboratory manual. 2nd ed. Cold Spring Harbor Laboratory Press, 1989:16-34.

26 Zhao LJ, Liu HQ, Cao J, et al. Activation of intracellular MAPK/ ERK initiated by hepatitis C virus envelope protein E2 in HepG2 cells. Acta Biochimica et Biophysica Sinica 2001; 33(6):691-5.

27 Ladner RC. Constrained peptides as binding entities. Trends Biotechnol 1995; 13:426-30.

28 Lowman HB. Bacteriophage display and discovery of peptide leads for drug development. Annu Rev Biophys Biomol Struct 1997; 26:401-24.

29 Wrighton NC, Farrell FX, Chang R, et al. Small peptides as potent mimetics of the protein hormone erythropoietin. Science 1996; 273 (5274):458-64.

30 Smith GP, Scott JK. Libraries of peptides and proteins displayed on filamentous phage. Methods Enzymol 1993; 217: 228-57. 